\title{
RISK FACTORS OF CANCER AND HOW TO PREVENT
}

\author{
Dr. Mohamed Soliman Gaber MD. Dr. Raafat Abd El-aal Bakheet MD. \\ DR.Fatma Ibrahim Mahmoud El Ghazali M.B. B.Ch. \\ CLINICAL ONCOLOGY DEPARTMENT.SOHAG FACULTY OF \\ MEDICINE.SOHAG UNIVERSITY.EGYPT. \\ Corresponding author; Fatma GTA \\ Clinical oncology Department, Sohag Faculty of Medicine, Sohag University, Egypt.
}

\begin{abstract}
Cancers are a large family of diseases which involve abnormal cell growth with the potential to invade or spread to other parts of the body. They form a subset of neoplasms. The aim of the work to show the magnitude of the problem of cancer, The possible etiologic causes of cancer in general as the great majority of cancers, are due to environmental factors. The remaining are due to inherited genetics. Common environmental factors that contribute to cancer death include tobacco (25-30\%), diet and obesity (30-35\%), infections (15-20\%), radiation (both ionizing and nonionizing, up to $\mathbf{1 0 \%}$ ), stress, lack of physical activity, and environmental pollutants. How to early detect cancer and Screening of the general population. Preventive measures applied certain types of cancer such as diet,medications, vitamins and vaccines.
\end{abstract}

\section{Introduction}

Cancers are a large family of diseases which involve abnormal cell growth with the potential to invade or spread to other parts of the body.[1] They form a subset of neoplasms.

\section{CANCER RISK FACTORS:}

\section{Obesity and Physical Activity}

The International Agency for Research on Cancer (IARC), after reviewing the epidemiological studies spanning over 30 years, concluded that obesity has a causal link with various forms of cancer. For example Obesity is an established breast cancer risk factor among postmenopausal, but not premenopausal women. [26]

\section{Tobacco}

Cigarettes are the main type of tobacco product consumed in the world. Cigars and pipes are still used. Water pipes are increasing in popularity in the United States. Cigar and/or pipe smoking cause cancers of the oral cavity, oropharynx, hypopharynx, larynx, and esophagus, with the risk being similar to that of cigarette smoking. Cigar and/or pipe smoking are causally associated with lung cancer and possibly with cancers of the pancreas, stomach, and urinary bladder.[45]

\section{Viruses}

According to some authors, viruses are one of the most important risks factor for cancer development in humans, second only to tobacco use.Infection by some hepatitis viruses, especially hepatitis B and hepatitis C, can induce a chronic viral infection that leads toliver cancer (59) Human papillomaviruses (HPV) are another particularly common cancer-causing virus. HPV is well known for causing genital warts and essentially all cases of cervical cancer, but it can also infect and cause cancer in several other parts of the body, including the larynx, lining of the mouth, nose, and throat, anus, and esophagus.[60]

\section{Cancer Susceptibility Syndromes}

A cancer syndrome or family cancer syndrome is a genetic disorder in which inherited genetic mutations in one or more genes predispose the 
affected individuals to the development of cancers and may also cause the early onset of these cancers. These are some examples:

- Hereditary breast-ovarian cancer syndrome (HBOC) is an autosomal dominant genetic disorder caused by genetic mutations of the BRCA1 and BRCA2 genes. In women this disorder primarily increases the risk of breast and ovarian cancer, but also increases the risk of fallopian tube carcinoma and papillary serous carcinoma of the peritoneum. In men the risk of prostate cancer is increased. Other cancers that are inconsistently linked to this syndrome are pancreatic cancer, male breast cancer, colorectal cancer and cancers of the uterus and cervix. (83) Familial adenomatous polyposis (FAP) is an autosomal dominant syndrome that greatly increases the risk of colorectal cancer. Around 1 in 8000 people will have this disease and it has approximately $100 \%$ penetrance. [84] Hereditary non-polyposis colon cancer (HNPCC), also known as Lynch syndrome, is an autosomal dominant cancer syndrome that increases the risk of colorectal cancer.

Cancer Prevention and Screening

\section{A.Tobacco Use and the Cancer}

\section{Patient}

In cancer patients and survivors, the evidence is sufficient to infern a causal relationship between cigarette smoking and adverse health outcomes. Quitting smoking improves the prognosis of cancer patients.(92)

B.Role of Surgery in Cancer Prevention

The primary interventions for mutation carriers for highly penetrant syndromes, such as multiple endocrine neoplasia (MEN), familial adenomatous polyposis (FAP), hereditary nonpolyposis colorectal cancer (CRC), and hereditary breast and ovarian cancer syndromes, are primarily surgical.For example Patients at risk for breast Cancer, The most common cancer syndromes that place women at risk for breast cancer are BRCA1 and BRCA2 gene mutations. Following referral for genetic assessment(116) women is to pursue bilateral risk-reduction mastectomy with an option for immediate reconstruction. Bilateral salpingo-oophorectomy for BRCA 1 and BRCA2 mutation carriers may also be considered, as this procedure has been shown to reduce breast cancer risk by almost 50\% . [118]

\section{C.CANCER RISK-REDUCING} AGENTS (CHEMOPREVENTION)

Cancer risk reduction, commonly referred to as chemoprevention, is the use of a range of interventions from drugs to isolated dietary components to whole-diet modulation to block, reverse, or prevent the development of invasive cancer.[143]

\section{MICRONUTRIENTS}

Micronutrients comprise a large, diverse group of molecules typically ingested as part of the diet that play roles in normal human biology. This group of compounds has been investigated extensively as cancer risk-reducing agents in purified forms (i.e., supplements), as components of multiagent cocktails, and occasionally, as components of food extracts/other mixtures.

\section{Calcium and Vitamin D}

Observational epidemiologic studies have shown a relatively consistent inverse association between low calcium intake, including that from supplements, and increased colorectal and colon cancer risk. [153]

EPIGENETIC

TARGETING AGENTS :

\section{Selective Estrogen Receptor} Modulators: such as: Tamoxifen

The clinical finding that tamoxifen reduces the incidence of contralateral second primary breast cancers during 
adjuvant treatment regimens catalyzed the push for its development as a cancer risk-reduction agent. [161]

\section{5a-Steroid Reductase Inhibitors}

The $5 \alpha$-steroid reductase inhibitors, finasteride and dutasteride, prevent or delay carcinogenesis progression in the prostate, yet progression of high-grade lesions is unaffected. Use of finasteride for a period of 7 years reduced the incidence of prostate cancer but did not significantly affect mortality. [166]

\section{D.Cancer Screening .1 BREAST CANCER}

Mammographies, clinical breast examinations (CBE) by a health-care provider, and breast selfexaminations (BSE) have long been advocated [184] for the early detection of breast cancer. In recent years, ultrasound, magnetic resonance imaging (MRI), and other technologies have been added to the list of proposed screening modalities. [184]

\section{COLON CANCER SCREENING}

Today, fecal occult blood testing (FOBT), stool DNA testing, flexible sigmoidoscopies, colonoscopies, and CT colonographies and, occasionally, barium enemas are all used in colorectal cancer screening. MRI colonoscopy is in development. Randomized trials have demonstrated that endoscopic polypectomies reduce the incidence of colorectal cancer by about 20\% . [194]

\section{E. Genetic Counseling}

The goals of this process include providing the client with an assessment

\section{CONCLUSION}

It is nearly impossible to prove what caused a cancer in any individual, because most cancers have multiple possible causes. Cancer prevention is defined as active measures to decrease the risk of cancer.The vast majority of cancer cases are due to environmental risk factors,. Thus, cancer is considered a largely preventable disease. Greater than $30 \%$ of cancer of individual cancer risk, while offering the emotional support needed to understand and cope with this information.(225)

\section{F.Cancer Vaccines}

Cancer vaccines are medicines that belong to a class of substances known as biological response modifiers. Biological response modifiers work by stimulating or restoring the immune system's ability to fight infections and disease. There are two broad types of cancer vaccines:

Preventive (or prophylactic) vaccines, which are intended to prevent cancer from developing in healthy people; and Treatment (or therapeutic) vaccines, which are intended to treat an existing cancer by strengthening the body's natural defenses against the cancer [239].

1. The U.S. Food and Drug Administration (FDA) has approved two preventive vaccines, Gardasil ${ }^{\circledR}$ and $\underline{\text { Cervarix }}{ }^{\circledR}$, that protect against infection by the two types of HPV - types 16 and 18 - that cause approximately $\mathbf{7 0}$ percent of all cases of cervical cancer worldwide.

2. In April 2010, the FDA approved the first cancer treatment vaccine. This vaccine, sipuleucel$\underline{\mathrm{T}}$ (Provenge ${ }^{\circledR}$, manufactured by Dendreon), is approved for use in some men with metastatic prostate cancer.(2)

deaths could be prevented by avoiding risk factors including: tobacco, overweight / obesity, an insufficient diet, physical inactivity, alcohol, sexually transmitted infections, and air pollution. Also there is role of surgery,chemoprevention ,medication ,genetic councelling, screeningand vaccination in cancer prevention. 


\section{REFERENCES}

1. Cancer Fact sheet No297". World Health Organization. February 2014. Retrieved 10 June 2014.

2. Vainio $H$, Bianchini $F$, eds. Weight control and physical activity, vol. 6. IARC Handbooks of Cancer Prevention. Lyon, France: IARC Press, 2000.

3. International Agency for Research on Cancer. Tobacco smoke and involuntary smoking. IARC Monographs on the Evaluation of Carcinogenic Risks to Humans, vol. 83. Lyon, France: IARC, 2004:1179.

4. Sung, Max W; Thung, Swan N; Acs, George (2000). "Hepatitis Viruses". In Bast RC, Kufe DW, Pollock RE, et al. Holland-Frei Cancer Medicine (5th ed.). Hamilton, Ontario: B.C. Decker. ISBN 1-55009-113-1

5. McLachlin, Catherine M; Crum, $\begin{array}{lll}\text { Christopher } & P & \text { (2000). }\end{array}$ "Papillomaviruses and Cervical Neoplasia". In Bast RC, Kufe DW, Pollock RE, et al. Holland-Frei Cancer Medicine (e.5 ed.). Hamilton, Ontario: B.C. Decker. ISBN 1-55009-113-1.

6. Smith EC (2012). "An overview of hereditary breast and ovarian cancer syndrome". J Midwifery Womens Health $57 \quad$ (6): 577-84. doi:10.1111/j.15422011.2012.00199.x. PMID 23050669.

7. Macrae F, du Sart D, Nasioulas S (2009). "Familial adenomatous polyposis". Best Pract Res Clin Gastroenterol 23 (2): 197-207. doi:10.1016/j.bpg.2009.02.010. PMID 19414146.

8. U.S. Department of Health and Human Services. The Health Consequences of Smoking - 50 Years of Progress: A Report of the Surgeon General. Atlanta: U.S. Department of Health and Human Services, Centers for Disease Control and Prevention, National Center for Chronic Disease Prevention and Health Promotion, Office on Smoking and Health; 2014

9. Guillem JG, Wood WC, Moley JF, et al. ASCO/SSO review of current role of risk-reducing surgery in common hereditary cancer syndromes. J Clin Oncol 2006;24:4642-4660.

10.Domchek SM, Friebel TM, Singer CF, et al. Association of risk-reducing surgery in BRCA1 or BRCA2 mutation carriers with cancer risk and mortality. JAMA 2010;304:967-975.

11. Greenwald P, Kelloff G. The role of chemoprevention in cancer control. IARC Scientific Publications (Lyon) 1996;139:13-22.

12.McCullough M, Robertson AS, Rodriguez C, et al. Calcium, vitamin D, dairy products, and risk of colorectal cancer in the cancer prevention study II nutrition cohort (United States). Cancer Causes Control 2003;14:1-12.

13. Fisher B, Redmond C. New perspective on cancer of the contralateral breast: a marker for assessing tamoxifen as a preventive agent. J Natl Cancer Inst 1991;83:1278-1280.

14. Thompson IM Jr, Goodman PJ, Tangen $\mathrm{CM}$, et al. Long-term survival of participants in the prostate cancer prevention trial. $\mathrm{N}$ Engl $\mathrm{J}$ Med 2013;369:603-610.

15. Shapiro S. Periodic screening for breast cancer: the HIP Randomized Controlled Trial. Health Insurance Plan. J Natl Cancer Inst Monogr 1997:27-30.

16. Schoen RE, Pinsky PF, Weissfeld JL, et al. Colorectal-cancer incidence and mortality with screening flexible sigmoidoscopy. N Engl J Med 2012;366:2345-2357.

17. Brierley KL, Blouch E, Cogswell W, et al. Adverse events in cancer genetic testing: medical, ethical, legal, and financial implications.cancer $\mathbf{J}$ 2012,18:303-309. 
18.Lollini PL, Cavallo F, Nanni P, Forni G. Vaccines for tumour prevention. Nature Reviews Cancer 2006; 6(3):204-216. [PubMed Abstract]

19.. Anand $\mathrm{P}$, Kunnumakkara AB, Kunnumakara AB, Sundaram C,
Harikumar KB, Tharakan ST, Lai OS, Sung B, Aggarwal BB (September 2008). "Cancer is a preventable disease that requires major lifestyle changes". Pharm. Res. 25 (9): 2097-116. doi:10.1007/s11095-008-9661-9. PMC 2515569. PMID 18626751. 
